\title{
The "Inverted U-shaped" Hypothesis of Urban- Rural Income Gap in the Process of Urbanization: Empirical Testing and Policy Implications
}

\author{
Yeying HONG ${ }^{1,2}$ \\ ${ }^{1}$ School of Ethnology and Sociology \\ Guizhou Minzu University \\ Guiyang City in Guizhou Province, China \\ ${ }^{2}$ District Research Office \\ Fuling school of Administration \\ Fuling district in Chongqing, China \\ Email:hyeying123@163.com
}

\begin{abstract}
How urbanization affects the regional economic development. And it has been praised by educational world attention, especially the current unbalanced development. This is not fully the most outstanding performance as the gap between urban and rural areas, and the main performance in the income gap between urban and rural areas. Article selected ethnic are as in Guizhou province in 2000-2016 year series data as the foundation, that using multiple regression analysis method of residents' income gap between Urban and Rural areas in Guizhou province urbanization whether meet the "inverted $U$ " hypothes is has carried on the empirical analysis. The results showed that: Guizhou province Urbanization and Urban-rural income gap exis ts between the irregular "inverted $U$ " hypothes is, which shows the characteristics of the trend of the "M" type. Key measures to narrow the gap between urban and rural residents income, we must promote the building of the new Urbanization. This requires:(1)Optimization of mountain characteristic industrial supporting ability of urbanization, promote absorbing employment ability.(2)Synergy advancing precision for poverty alleviation and new urbanization development, equal to improve human capital investment of urban and rural residents.The innovation of this article: (Selected case studies, which has certain representativeness;(2)In economic less developed and underdeveloped minority areas inspection is in accordance with the "inverted $U$ " hypothesis of adaptation.
\end{abstract}

Keywords-Urbanization; Urban-rural income disparities; The inverted U hypothesis; Guizhou Province

\section{INTRODUCTION}

How urbanization rate affect China's income gap between urban and rural areas has been praised by practice and theoretical concerns.According to China statistical yearbook data show that China's urban and rural residents per capita disposable income than from 2.57 in 1978:1 to 3.33 in 2007:1, after the present trend, in 2016 to $2.72: 1$, it has experienced an inverted "U" glyph development path. The widening income gap will not only inspire many social contradictions and distorted social fair and just, and may lead to social conflict and political instability.As the party's 1978 year report clearly put forward the social principal contradictions of our country has been converted to the good life is people's increasing needs and not balance the contradiction between the inadequate development, unbalanced development and the current inadequate most outstanding performance is the gap between urban and rural areas, the main performance in the urban and rural residents income gap.So, questions are being asked in the economic underdeveloped, owed to the development of national regions is in line with the "inverted U" hypothesis of adaptability, therefore, it is a realistic problem needs to be academic discussion and in-depth research.

At present the academic circles in the new urbanization "inverted U" hypothesis of the income gap between urban and rural areas have a certain research, pay more attention to national macro level, economy is relatively developed areas, ignored the study of southwest ethnic minority areas, it requires us to further explore and perfect.Through literature analysis, on the income gap between urban and rural areas in the new urbanization of "inverted $U$ " hypothesis is mainly manifested in two aspects:One is that there is "inverted U" hypothesis. ${ }^{[1-4]}$ The oher is does not exist "inverted U" hypothesis. ${ }^{[5-6]}$ The income gap between urban and rural areas affected by what factors and the degree of effect how?Many scholars mainly from national macro level or the central, provincial economy is relatively developed eastern to research on the relationship between them.Provincial new urbanization in national regions of urban and rural income gap exists in the "inverted U hypothesis" feature has yet to be further verified.Therefore, this paper attempts to ethnic areas of Guizhou province as the research object, explore new type of urban and rural residents income gap exists in the process of the urbanization of "inverted U" hypothesis, aims at providing a similar background area how to effectively use for reference to promote the steady development of the new type of urbanization.

We implement the strategy of rejuvenating the country, which is with a $\mathrm{Xi}$ Jinping gas the core of the CPC central committee on the party and national business globally, and making new deployment for the work in the "three rural", and 
put forward new requirements. What rural labor force transfer to cities and non-agricultural employment is that the dual social structure transformation inevitable phenomenon in developing countries, and it also the current advance of urbanization and new rural revitalization of the coordinated development of the key. Current studies of rural labor transfer and poverty reduction effect of the system analysis results are not much, and pay more attention to national macro level, with economic developed area, less study of ethnic minority areas, it needs to further explore and perfect. Guizhou province is located in the typical karst landform areas, which it a typical multiracial province, and the largest poverty, apparent return rate is the most poverty, poverty, poverty the most provinces, and it crucial for poverty alleviation in China area, demonstration area and the battle zone. In 2016, poverty reduction to pick a hat 6 counties in Guizhou, 1.21 million folks out of poverty population, but the poverty rate which is as high as $10.8 \%$, rural poverty population of 3.7776 million folks, accounting for $19.03 \%$ of the rural population. Total employment of 19.8372 million folks, including the primary industry professionals 11.3687 million people, accounting for $57.31 \%$ of total employment. At the same time, June 1, 2015, Guizhou cancelled agricultural and non-agricultural household register, unified registration for residents registered endless residence, so as to create more for the rural population transfer conditions. Research results to rural revitalization and similar regional background of national minority poverty reduction effectively combine to provide decision-making reference.

\section{StUdy DESIGN AND THE SELECTION OF VARIABLES}

\section{A. Variable measurement}

1) Index of the income gap between urban and rural areas Generally, urban and rural residents income gap, the greater the explain the farmers' income is low, also limits the farmer labor skills of ascension, which is bad for poverty reduction. The current academic circles of urban and rural residents income gap measure methods mainly include the ratio of urban and rural residents per capita disposable income, the gini coefficient and tal index, and argues that thayer index not only can directly reflect the urban and rural population, but also can effectively reflect the changes on both ends of the urban and rural income. Therefore, we select the Wang Ruipeng etc. of the research results, ${ }^{[7]}$ and using thayer index to measure the income gap of residents in urban and rural. By $\mathrm{T}$, Formula is as follows:

$$
T=\frac{a I_{I} L \mathrm{Ln} I_{\mathrm{u}}+(1-a) I_{\mathrm{Ln}} I_{r}}{a I_{\mathrm{u}}+(1-a) I_{\mathrm{r}}}-\operatorname{Ln}\left[a I_{\mathrm{u}}+(1-a) I_{\mathrm{r}}\right]
$$

To explore the theory of urbanization inflection point values, the need for urbanization rate derivative (a), When $d$ $(\mathrm{T}) / \mathrm{d}(\mathrm{a})=0$, $\mathrm{T}$ value the most.

$$
\alpha^{*}=\frac{\left(I_{u} / I_{r}\right) \times \operatorname{Ln}\left(I_{u} / I_{r}\right)-\left(I_{u} / I_{r}\right)+1}{\left[\left(I_{u} / I_{r}\right)-1\right] \times\left[\left(I_{u} / I_{r}\right)-1\right]}
$$

Type in $\alpha$ population urbanization rate, $I_{u^{-}}$urban residents per capita disposable income (Yuan), Ir-Rural residents per capita disposable income (Yuan).

\section{2) Urbanization rate}

Land and population urbanization is mainly composed of two elements, the academic study of population urbanization were higher, therefore, urbanization is mainly discussed in this article refers to the population urbanization.Therefore, this article makes reference to the research achievements of yeung sum equal. ${ }^{[8]}$ The permanent population proportion of the population to measure the urbanization rate,SO we used to represent $\alpha$.

\section{B. The data source}

This article selects the income gap between urban and rural areas of Guizhou province in 2000-2000, as explained variable, namely choose thayer index to measure, by T.Variables are: $\mathrm{P}_{\mathrm{u}}$ Urban population (people); $\mathrm{P}_{\mathrm{r}}$ The rural population (people); $\mathrm{I}_{\mathrm{u}}$ _Urban residents per capita disposable income (yuan); $\mathrm{I}_{\mathrm{r}} \_$Rural residents per capita disposable income (yuan).The index selection of data are come from Guizhou province statistics yearbook (2001-2017), the 2017 statistics bulletin of the national economy and social development in Guizhou and other statistical data published by the department .

\section{THE EMPIRICAL ANALYSIS}

\section{A. The basic situation of the study area}

Guizhou province is located in the typical karst landform areas, is a typical multiracial province, is also one of the national famous concentrated most needy area.As of late 2016, the resident population of 35.55 million people in Guizhou, the population urbanization rate of $44.15 \%$.In 2016, the national urban and rural income ratio is 2.72, and the income ratio between urban and rural areas in Guizhou is 3.31, 1.22 times the national average.Visible, as ethnic areas in Guizhou ethnic diversity, cultural diversity and poor representativeness and other characteristics, is the southwest national area and even the whole country backward province of urban and rural residents income gap.At the same time, the population urbanization in Guizhou province from 2000 to 2016 rate from $23.87 \%$ to $23.87 \%$, and the ratio of urban and rural residents income gap fell from 3.73 to 3.31.Puzzling is that the income gap between urban and rural areas in the new urbanization in Guizhou is "U" curve hypothesis.Therefore, it is a subject worth in-depth research.

\section{B. New income gap between urban and rural areas in the process of the urbanization of the applicability of the law of "inverted $U$ " analysis}

Based on the Guizhou statistical yearbook data as the foundation,Urbanization rate between 2000 and 2016, urban residents per capita disposable income and rural residents per capita disposable income of the sample data,Thayer index that evaluates to the income gap between urban and rural areas in Guizhou, the results are shown in table 1 and Fig. 1.

1) The income gap between urban and rural areas in Guizhou province from 2000 to 2016 and the change trend

Since the implementation of west development, along with the constant improvement of the urbanization process, the 
income gap of urban and rural residents in Guizhou show a similar trend of the " $\mathrm{M}$ " type the first rise, fall, after then rebounded, finally presents a downward trend.By the data in table 1, from 2000-2016, the population in cities and towns in Guizhou rate by $23.87 \%$ to $23.87 \%$, increased by $20.28 \%$, maintain stable growth trend.Urban and rural residents per capita net income gap than by 3.73 times in 2000, up from 4.59 times in 2006, at its highest point, and volatility after recovery, thus showing a slow fall to 3.31 times in 2016.From 2000 to 2016, the per capita income of urban and rural residents in Guizhou is fluctuating around 4 times, 17 years than the average per capita net income of urban and rural residents is 3.98 times.Since 2014, the population urbanization rate reached $40.01 \%$ in Guizhou, and rapid urbanization into "development stage".

TABLE I. FROM 2000 TO 2016 IN GUIZHOU PROVINCE URBANIZATION AND URBAN AND RURAL RESIDENTS INCOME GAP RELATIONSHIP

\begin{tabular}{|c|c|c|c|c|c|c|c|c|c|}
\hline variable time & 2000 & 2005 & 2010 & 2011 & 2012 & 2013 & 2014 & 2015 & 2016 \\
\hline Urbanization rate $\%$ & 23.87 & 26.87 & 33.81 & 34.96 & 36.41 & 37.83 & 40.01 & 42.01 & 44.15 \\
\hline $\begin{array}{l}\text { The theory of a } \\
\text { tuming point } / \% \\
\text { The income gap }\end{array}$ & 29.27 & 27.16 & 28.03 & 28.35 & 28.51 & 28.98 & 30.66 & 30.88 & 30.98 \\
\hline $\begin{array}{l}\text { between urban and } \\
\text { rural areas }\end{array}$ & 3.73 & 4.34 & 4.07 & 3.98 & 3.93 & 3.80 & 3.38 & 3.33 & 3.31 \\
\hline Thayer index & 0.21 & 0.26 & 0.24 & 0.23 & 0.22 & 0.21 & 0.17 & 0.17 & 0.16 \\
\hline
\end{tabular}

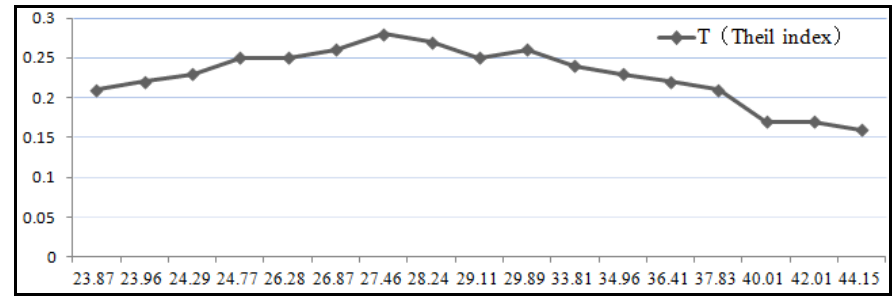

Fig. 1. From 2000 to 2016 in Guizhou province population urbanization rate and the thayer index relationship

2) The income gap of urban and rural residents in Guizhou in 2000-2016 "inverted U" the applicability of the analysis

From table 1,From 2000 to 2006 in Guizhou province in the process of the urbanization of widening income gap between urban and rural areas,Population urbanization rate rose from $23.87 \%$ in 2000 to $27.46 \%$ in 2006. Thayer index value increased from 0.21 in 2000 to 0.28 in 2006.Accordingly, in this stage the relationship between population urbanization and urban and rural residents income gap should be in line with the "inverted U" curve characteristics, and in the left hemisphere of the "inverted U".According to the "inverted U" change rule,Since 2006, the income gap of urban and rural residents in Guizhou should show obvious trend, but that is not the case,Can be seen from Fig. 1, 2007-2009, with the gradual improvement of the urbanization level, the income gap between urban and rural areas in Guizhou, does not seem to be shrinking, but present a higher level float back and forth, tal index value to get the highest (0.26) in 2009.After 2009, the income gap between urban and rural areas in Guizhou showed obvious trend.Therefore, this one phase analysis,In 2007-2009 the relationship between urbanization and urban-rural income gap in Guizhou is not in line with the "inverted U" curve characteristics. Why the Guizhou province population urbanization rate across the inflection point value (2006), the theory and the income gap between urban and rural areas also presents the expansion wave phenomenon?Research indicates that the "inverted $U$ " type curve is the outcome of combined action of multiple factors. ${ }^{[9]}$

Therefore, we think that in addition to urbanization level influence the income gap between urban and rural areas, to some extent also influenced by other factors.However, this study investigates the income gap between urban and rural areas in urbanization is in line with the "inverted U" hypothesis, what are the exact nature of the influence factors of the income gap between urban and rural areas, is not a research emphasis of this article, will be discussed in later articles of this problem.

\section{CONCLUSION AND POLICY MEANING}

\section{A. Conclusion}

Article aims to explore new type of urbanization in Guizhou in 2000-2016 the income gap between urban and rural areas in the presence of "inverted U" curve characteristics. The results show that the Guizhou province urbanization and urbanrural income gap exists between the irregular "inverted U" hypothesis, which shows the characteristics of the trend of the "M".To some extent, explain the Guizhou province in the building "a nucleus, a group of, two laps, six group, the more" as the main body of the provincial urbanization in an open space system in effective, mechanism, at the same time, through the establishment and cost of providing basic public services, enhance agricultural transfer of population of social integration, reasonable guide innovation such as the household registration management system of long distance across the province urbanization policy initiatives on the narrow the gap between the income of urban and rural residents has certain feasibility and correctness.However, to reduce the area of urban and rural residents income gap requires a variety of policy of mutual cooperation and collaboration to get effective play.Such as the national level, the need to reform the income distribution system;Micro level, the area of low-income groups can make such policy support.

\section{B. Policy suggestion}

The development of urban and rural areas has always been to promote each other and contact each other, urban and rural areas should be belong to a community of destiny.Team to build a well-off society in an all-round way, so to speak, to be in, the basic to realize the modernizations in agriculture and rural areas have to narrow the gap between urban and rural.Combined with the national characteristics of natural and cultural resources advantage, the key to optimize mountain characteristic industrial supporting ability of urbanization, promote human capital investment of urban and rural residents equal to reverse its not narrowing but expanding income gap between urban and rural areas "elephant", promote the coordinated development of urban and rural integration.Visible, it has strong policy significance, mainly under the table in the following two aspects: 
1) Optimization of mountain characteristic industrial supporting ability of urbanization, promote absorbing employment ability. Industry is supported in the development of urbanization, urban is the carrier of industry development, go have a characteristic, diversification, intensive, follow a new path of sustainable development of urbanization in Guizhou.To narrow the gap between the income of urban and rural residents, promote the development of the urban and rural integration, it must increase farmers' income.This requires, do the following work:First, grasp the leading industry, pay attention to cultivate the new type of agricultural management main body.By relying on the existing industrial park, optimize the industrial structure layout, strengthen industrial supporting ability, give play to effect of industrial agglomeration and dislocation development;We focus on is given priority to with domestic demand the transfer of capital, technology intensive industry, actively guide labor-intensive industries gradient to the surrounding areas, promote rural labor to the industrial park, urban agglomeration.In addition, around the local planting, breeding, rural tourism and rural electricity industry development, concentrating on agricultural leading enterprises and farmers' professional co-operatives, mountain characteristics of agricultural enterprises and rural small enterprises such as new type of agricultural management main body, help poor rural labor employment at home nearby, expand the income channels.Second, strengthen the characteristics of the new urbanization strategy of industrialization driving characteristics of mountain.Such as strengthen the development of Guizhou ethnic characteristics advantage, light industry bigger and stronger in liquor, tea, tobacco, specialty and the "five card" national pharmaceutical industry development, as soon as possible into a typical, nationality characteristics such as light industry development base, improve the ability to absorb employment of industry, and boost employment.Third, with the model of 'Internet +", push forward new formats of the third industry.Cultivation with big data as the lead, in line with market demand in Guizhou ethnic culture tourism resources and the characteristics of mountain culture, fully dig characteristic tourist town and reveal the market value of the national customs WenHua Town, build "colorful Guizhou wind mountain park, province" brand, expand employment, improve the rural residents asset income, wage income and other comprehensive income.In addition, fully integrated use of national culture resources, cultivate and carry forward the national folk culture as the core of rural folk tourism economic development of new formats, strive to create a set of agricultural ecological sightseeing, high-quality goods picking garden, leisure entertainment and folk cultural tourism demonstration base, as "a town in fujian, the joy of country folk custom villages" characteristic brand, achieve "win-win" of material civilization and spiritual civilization.

2) Synergy advancing precision for poverty alleviation and new urbanization development, equal to improve human capital investment of urban and rural residents. To effectively promote the development of mountainous characteristics of new type of urbanization in national regions, we must strive to enhance the level of the equalization of urban and rural education development.This requires, do the following work: The first, and promote the development of the integration of urban and rural education, the thorough implementation of rural education promotion project.Vigorously develop the rural preschool education, in accordance with the "big administrative villages built independent, small joint administrative villages of kindergarten", strive to amplify public preschool education resources, speed up the elimination of rural kindergarten taipans frontal phenomenon.And strengthen the weak school conditions of running a school in rural compulsory education in poverty-stricken areas funds investment, speed up the construction in accordance with standardized boarding schools in rural areas, and synchronization in poor rural teachers support plan.Second, to promote the modern vocational and technical education and training services for the whole.Relying on the vocational college, the mechanic college, enterprises and other training institutions, to establish a migrant pioneer park, guide and promote the poor masses, especially the low culture, the skills, weak group of migrant workers and rural surplus labor's employment and entrepreneurial skills, post skills upgrading training.To have labor ability of colleges and universities, vocational colleges, such as youth groups, more efforts, through various channels to provide public employment services, expand employment breadth.The transfer of agricultural population to conform to the policy, according to the corresponding policies for venture funds guarantee loan, interest and other comprehensive services, cultivate a new generation of industrial workers.Actively promote the employment workshop, change of relocation sites for poverty alleviation focus on new forms of employment, especially to strengthen the employment of change of relocation poverty population and skills training, stimulate endogenous motivation and employability.Third, focus on raising the level of human capital in rural special groups.Special groups of countryside employment ability, modern vocational and technical training, and the training into the normalized management.

\section{ACKNOWLEDGMENT}

This work was sponsored by Graduate student scientific research fund project of Guizhou in 2017 "Guizhou province rural poverty and anti-poverty governance innovation research"(KYJJ2017027).

\section{AUTHOR IN BRIEF}

HONG, Yeying, male, People in Shucheng City of Anhui Province, China; Doctoral student of Guizhou Minzu University, Chongqing Fuling School of Administration. Corresponding author.

\section{REFERENCES}

[1] Anand S. The Kuznets process and the inequality devel-opment relationship[J]. Journal of Development Eco-nomics, 1993(40). (In Chinese).

[2] Glomm G. A model of growth and migration[J]. Canadi-an Journal of Economics, 1992(5). (In Chinese).

[3] CHEN Zongshen.About the income difference inverted $U$ curve and a few methods in the study of polarization problem[J].Chinese academy of social sciences, 2002(5). (In Chinese).

[4] [7][9]WANG ruipeng, Hong-hui zhu.Study on the relationship between urbanization and urban-rural income gap in xinjiang[J].Statistics and decision making, 2016(12) . (In Chinese).

[5] WANG Jiangui.The phenomenon of the $U$ is an economic law?[J].Economic Research, 2000(7) . (In Chinese). 
[6] Khan A R, riffin $\mathrm{K}$, iskin C, hao R. Household income and its distribution in China[J]. The China Quar-terly, 1992(32).
[8] YANG Senping fen-fen tang, Wu Xu.Study on the relationship between urban and rural income gap and urbanization rate[J].Economic and financial management, 2015(11). (In Chinese). 